\title{
The Nature of Fiction/al Utterances
}

\author{
Aberto Voltolini \\ Professore Ordinario, University of Torino \\ alberto.voltolini@unito.it
}

\begin{abstract}
In this paper, first of all, I want to try a new defense of the utterance approach as to the relationship between fictional and nonfictional works on the one hand and between fictional and nonfictional utterances on the other hand, notably the idea that the distinction between fictional and nonfictional works is derivative on the distinction between fictional and nonfictional utterances of the sentences that constitute a text. Moreover, I want to account for the second distinction in minimally contextualist semantic terms. Finally, I want to hold that what makes a fictional utterance, hence a fictional work, properly fictional is the contextually pre-semantic fact that its utterer entertains an act of make-believe, where such an act is accounted for in metarepresentational terms. This ultimately means that the fiction/nonfiction distinction is not clarified in terms of the fictional works/nonfictional works distinction, for things rather go the other way around.
\end{abstract}

Keywords fiction/nonfiction, fictional/nonfictional works, utterance approach, minimally contextualist account, metarepresentation.

DOI 10.1515/kjps-2016-0016

\section{Introduction}

In this paper, first of all, I want to try a new defense of the utterance approach as to the relationship between fictional and nonfictional works on the one hand and between fictional and nonfictional utterances on the other hand, notably the idea that the distinction between fictional and nonfictional works is derivative on the distinction between fictional and nonfictional utterances of the sentences that constitute a text. Moreover, I want to account for the second distinction in minimally contextu- 
alist semantic terms. A fictional utterance of a sentence consists in that sentence paired with a narrow context of interpretation whose 'world' parameter is saturated by a fictional world, so as to yield for that sentence certain fictional truth-conditions; a nonfictional utterance of a sentence consists in that sentence paired with a narrow context of interpretation whose 'world' parameter is saturated by the actual world, so as to yield for that sentence certain real truth-conditions. Finally, I want to hold that what makes a fictional utterance, hence a fictional work, properly fictional is the contextually pre-semantic fact that its utterer entertains an act of make-believe, where such an act is accounted for in metarepresentational terms. This ultimately means that the fiction/nonfiction distinction is not clarified in terms of the fictional works/nonfictional works distinction, for things rather go the other way around.

\section{Fictional Utterances Have Pride of Place}

In the recent literature at the intersection between aesthetics and philosophy of language and mind, a longstanding debate on the nature of fiction has being renewed: what does fiction consists in? Since a great amount of our fictional practices has to do with narrative items, a natural way of approaching this debate is by asking another question: how can we draw a principled distinction between fictional works and nonfictional works? In this respect, one may think that answering the second question sheds light on the first question as well.

Clearly enough, however, matters are intricate. On the one hand, works that are prima facie ranked as fictional may contain a considerable amount of historical bits of narration (principally, but non exclusively, so-called historical novels). On the other hand, works that are prima facie ranked as nonfictional may contain some amount of fictional narration, or even at least of an inventive one (e.g. literary historical works, works of so-called new journalism). In this respect, even scientific works may exhibit this kind of feature. A scientific work may contain the description of a thought experiment. If one takes such an experiment as a practice in which one imagines that something is the case, then also a scientific work turns out to be imbued with fiction, or at least with made-up elements. One may then say that most works are a mixture of history and, 
if not fiction, invention. Pace Deutsch (2000), invention is a broader category than fiction, faction as some have labeled it. ${ }^{1}$ For it limits itself to capture freely narrated writings that may correspond to no real fact. ${ }^{2}$

Both textual and semantic criteria to draw a distinction between fictional and nonfictional works have notoriously revealed not to be satisfying. Nor seem other accounts, either speechact-theoretical or pretense-theoretical ones, to fare any better. ${ }^{3}$ Prima facie at least: as regards those accounts, we will see in the next Section that matters have to be reconsidered.

On the basis of the seeming failure of the above accounts, Stacie Friend has recently $(2008,2011,2012)$ maintained that the quest for necessary and sufficient conditions in order for a work to be fictional is misplaced. In order for a work to be so classified, one must rather take it as belonging to a certain genre. Following Walton (1970), she holds that such a belonging depends on whether the work has features falling under one of the following characteristics: standard (having such features tends the work to be ranked in that genre), contra-standard (having them tends to rule the work out of the genre), or variable (the fact that a work has such features has no bearing on its belonging to the genre in question).

Friend's way of putting things nicely copes with the intricacies I pointed out before. A fictional work that contains many historical bits of narrative is just contra-standard for its genre, namely that of a fictional work. Conversely, the same holds as to a historical work, or even to a scientific one, which contain some fictional bits of narrative: they are contra-standard cases of the opposite genre.

Truly enough, this way of classifying a work is highly contextual. ${ }^{4}$ Tacitus' narratives, which nowadays appear to be contra-standard examples of historical works because they contain several fictional elements, defi-

$1 \quad$ Cf. Geertz (1988:141).

2 Cf. Friend (2012:180), Davies (2012:68). In (2013), Deutsch restates his point, yet it still seems that his notion of invention covers more than the things that have to be properly labeled as fictional works.

3 For a review of these problems cf. e.g. Davies (2007), Sainsbury (2009).

4 Cf. on this Currie (2014:355), Kroon-Voltolini (2016). See also Friend herself (2011:177). 
nitely appeared to be standard examples of such works to the historian's contemporaries. Yet in this respect contextual shifts may even be more problematic. As Friend herself acknowledges, ${ }^{5}$ it may well be the case that a work originally classified as fictional passes on being classified as historical (possibly as a contra-standard case) and vice versa. An example of the former kind may be the tale of the Troy's siege The lliad is based on, which after Schliemann's archaeological discoveries may be used as a source of historical evidence. An example of the latter kind may be Geoffrey of Monmouth's Historia of Regum Britanniae, which is the first evidence of King Arthur's myth originally taken to be true history. For some, the Bible is another more convincing example of this kind. Now, if being a fictional work is a matter of context sensitivity in this radical sense, even appealing to genres does not seem to be very rewarding in order to deal with the fiction/nonfiction divide.

To be sure, Friend would reply that this kind of context-dependence precisely qualifies how things work with genres. In Walton's original example, Pablo Picasso's Guernica is now a standard case of the genre of painting, yet it may later turn out to be a contra-standard case of guernicas, where guernicas are the genre of works with "surfaces with the colors and shapes of Picasso's Guernica, but the surfaces are molded to protrude from the wall like relief maps of different kinds of terrain" (1970:347). Thus, it may well be the case that what is now ranked as a fictional work may be later ranked as a historical work, and vice versa. This is precisely the case, says Friend, with Simon Winchester's The Surgeon of Crowthorne: some of its features interest us if we classify it as fiction, some other of its features interest us if we classify it as nonfiction (2012:198).

Yet in the Guernica's case (or in The Surgeon of Crowthorne's case for that matter), what makes one change the genre attribution is the different similarity parameter with other things that is appealed to - if you like, a sort of Gestalt switch occurs in which different Gestalt properties of the work are grasped, as Walton says (1970:340). Its being violent, vital and disturbing makes Guernica be a case of paintings, while its being cold,

$\overline{5}$ See e.g. Friend (2008:164), (2012:198). 
lifeless and boring makes it a case of guernicas. ${ }^{6}$ But as to fictional vs. nonfictional works, the change in attribution may not depend on focusing a different similarity parameter, but simply in regarding them differently. ${ }^{7}$ Consider e.g. what I would label a lucid myth of creation, that is, a myth whose fictional and nonfictional elements were recognized respectively as such from its very beginning, yet it was taken as a historical work for a long while and as a fictional work afterwards. Some Maori myths may be examples of this kind (cf. Reed 2006). In conformity to Walton 1990:71, another such example may be William Prescott's History of the Conquest of Peru, the inventive narration of the famous Spanish enterprise in that part of Latin America. Thus, if as to genres appealing to context switches allows this kind of subjectivity, it does not seem to be very helpful in order to understand whether a work is fictional or not: for a work, being fictional or nonfictional seems ultimately to lie in the eye of the beholder. Let me draw the following comparison with a Wittgensteinian idea of concepts. According to Wittgenstein (1953), one may rank something under a certain concept if that something shares a family resemblance with other thing falling under that concept. Yet if it is just contextually the case that it shares that resemblance with those things, for in another context it shares that very resemblance with things falling under an opposite concept, than that sharing is not particularly useful for classifying purposes. Mutatis mutandis, the same holds as to things belonging to a genre. ${ }^{8}$

\footnotetext{
$6 \quad$ Cf. Walton (1970:347).
}

7 As Deutsch (2013:370) puts it, "the same manuscript can go from not being fiction to being fiction in the blink of a publisher's eye".

8 Currie (2014:361 n.32) suggests that the effect of relativity, or subjectivity, in the significance that prompts a contextual switch in a genre attribution may be due to the kind of imagination that is involved: mere propositional imagining in the historical case, perceptual imagery in the fictional case. I am uncertain whether this suggestion goes in the right direction. Yet as Friend herself underlines (2008:155-6), historical narratives may well be mentally dramatized and still remain historical. In order to weaken this subjectivity effect, Friend seems instead to appeal to conventions: "because these conventions change over time, what matters to the decision to write fiction or nonfiction also changes" (2008:166). Yet I am not sure whether such an appeal to conventions is appropriate. If in order to justify the switch one has to look for something socially shared, rather than to conventions I would appeal to something as vague as Weltanschauung and Zeitgeist. 
Granted, in order to rule out those problematic cases, Friend finally appeals to authorial intentions. ${ }^{9}$ The ludic attitudes of contemporary readers notwithstanding, she would say, the Historia of Regum Britanniae is a historical work, for so Geoffrey wanted it to be read. Geoffrey didn't want at all to tell a fictional story. By contrast, in reviving a certain tale, Homer (admittedly) wanted to tell a fictional story. Yet as is well known, intentions are tricky. Not only they may be missing - even if we put the question of Homer's intentions aside, who knows what the Bible's author(s) really wanted to write? - but they may be unsuccessful - while intending to write a pièce of fiction, for some unknown yet psychoanalyzable reasons an author may rather manage to tell an autobiography of a hidden period of her life ${ }^{10}$ - or even overridden ${ }^{11}$ - let us suppose that Homer wanted to tell true stories, yet his intentions notwithstanding, his poems are masterpieces of fiction. ${ }^{12}$

\section{Fictional Works Depend on Fictional Utterances}

On the basis of what we have seen in the previous Section, it seems that the prospects of finding a way to tell what is fictional from what is nonfictional by starting from a distinction between fictional and nonfictional works are rather dim. Yet in the literature there is at least another approach worth considering. Instead of starting from works and wondering which works are fictional and which are not such, one may start from utterances and speaking of fictional vs. nonfictional utterances originally

$9 \quad$ See Friend herself (2008:165), (2011:177), (2012:193-4). On this intentionalist way of interpreting Friend's position see also Deutsch (2013:369-70). From his own intentionalist perspective, Currie would surely approve this move. Cf. (2014:357).

10 For this problem cf. Sainsbury (2009:7).

11 As Friend herself acknowledges (2012:203).

12 As a matter of fact, Friend herself recognizes that in such a situation authorial intentions are not the only relevant factor for classification, for also "the conventions associated with contemporary categorization practices" count (2012:195). Yet it is hardly the case that, as Friend herself acknowledges, appealing to either of the above factors is enough. In the end, Friend indeed admits that there may be cases of texts that would be better classified both as works of fiction and of nonfiction (2012:205). Yet it seems to me that in order for one and the same text to be so doubly classified, one has to resort either to the pragmatic or to the semantic accounts I will appeal in the next Section under the general labeling of the utterance approach. 
and of fictional vs. nonfictional works derivatively, such works being the result of sentences being uttered in one way or in the other one.

In the literature, one has pursued this utterance approach in two ways, which have been already hinted at before, yet dismissed too quickly. Either one appeals to speech acts and says that what makes an utterance fictional is a certain kind of speech act, the fictive speech act if you like, which is performed in such an utterance. There are at least two ways of pursuing this appeal, either in intentional terms - the sui generis fictive speech acts essentially is a matter of a certain fictive intent, to be cashed out in Gricean terms (Currie 1990)13 - or in normative terms that speech act is basically a matter of complying with the appropriate norms that differ from the norms of assertion (Garcia-Carpintero 2013). Or one appeals to contexts of interpretation, the contexts providing for sentences their truthconditional interpretation, ${ }^{14}$ and says that what makes an utterance fictional is the fact that the sentence it utters is given a truthconditional content by interpreting it in accordance with a certain (narrow) ${ }^{15}$ context of interpretation, whose 'world' parameter is saturated by a world of fiction (Recanati 2000, Voltolini 2006a). This appeal to contexts is a way of reformulating both Searle (1975) and Walton (1990) pretense or make-believe accounts of fiction. For in this perspective, both Searle's idea that a fictional utterance is an utterance in which one typically modifies an assertion by pretending to assert something and Walton's idea that a fictional utterance is an utterance of a sentence embedded in a make-believe game are reformulated as saying that a fictional utterance is an utterance of a sentence interpreted in a fictional context whose 'world' parameter is saturated by the relevant world of pretense or make-believe. ${ }^{16}$

13 Literally, Currie links the fictive intent with a text as a whole (1990:46). Yet it is clear that in his conception the fictive intent qualifies a text insofar as it preliminarily affects its sentences when uttered in a particular way.

14 For this notion, see Predelli (2005).

15 For this specification see the next Section.

16 Currie (2014:352) instead classifies Searle's theory as a variant of the intentionalist account of the utterance approach. Clearly enough, unlike Walton's account, Searle's account is intentionalist, in that the pretense modification of a speech act is for him intentional. Nevertheless, I think that it is better to understand any pretense account in 
For the time being, I do not want to discuss which of the two ways of developing the utterance approach is the best one. I will come back on this issue in the next Section. Rather, I want to stress some interesting consequences of this approach.

The first consequence is one I have already recalled. According to this approach, the existence of a fictional work is derivative upon the existence of a fictional utterance, or better a series of such utterances. ${ }^{17}$ In order for a fictional work to exist, one sentence (if the work is just a one-sentence one, a minimal work let us say), or better a series of such sentences (since works are normally based ${ }^{18}$ on more than one sentence), must be uttered fictionally.

Secondly, a fictional utterance of one and the same sentence may be flanked by a nonfictional one. One may provide many examples of this situation. Consider a historical novel such as Alessandro Manzoni's The Betrothed. As any Italian reader well knows, chapter I of that novel starts with the following sentence:

(1) That branch of the Lake of Como, which turns toward the south between two unbroken chains of mountains, presenting to the eye a succession of bays and gulfs, formed by their jutting and retiring ridges, suddenly contracts itself between a headland to the right and an extended sloping bank on the left, and assumes the flow and appearance of a river.

(1) may be uttered nonfictionally, as a part of a (true) description of a certain area of Lombardy, the richest region in Northern Italy. Yet it may also be uttered fictionally, with a view on the fictional story that Manzoni is going to tell, as set in the Lombardian environment providing the stage

terms of context shift: a pretended assertion is a genuine assertion in a fictional context, a pretended order is a genuine order in a fictional context, and so on.

17 As various people have underlined: cf. Currie (1990), Davies (2007), Stock (2011). Davies (2015:43) labels it as the orthodox view of the scope of what a fictional work based on fictional utterances amounts to.

18 As we will see in the next Section, I take works as hybrid entities made both of utterances - sentences in (narrow) contexts - and of their truth-conditional interpretation. 
for such a story. Likewise, if we take the title inaugurating chap. I of bk. IX of Geoffrey of Monmouth's Historia of Regum Britanniae:

(2) Arthur succeeds Uther his father in kingdom of Britain, and besieges Colgrin

we may take it not only as a nonfictional utterance presenting an (actually false) description concerning some of the kings that ruled Britain after Christ's incarnation, but also as a fictional utterance talking about at least an individual merely existing in a fictional world, i.e., King Arthur.

Finally, by taking those two consequences together, a third consequence ensues. One and the same text, i.e., one and the same collection of the very same (syntactically individuated) sentences, may amount to two works, a fictional and a nonfictional one, depending on whether such sentences as a whole are uttered either fictionally or nonfictionally. ${ }^{19}$ This may well be the case of narratives that are both a form of historical testimony and a form of literary invention, such as e.g. Primo Levi's If This is a Man or Roberto Saviano's Gomorrah.

In this respect, a defender of this approach does not have to concede that a work may be a patchwork made both of fictional and of nonfictional utterances, as Currie (1990:48-9) instead accepts. ${ }^{20}$ As some people remark, if this approach were forced to yield this 'patchwork' account, this would be a serious limit for it. ${ }^{21}$ Yet I think that one may legitimately reject such a concession, ${ }^{22}$ for three reasons at least.

19 See also Walton (1990:71).

20 Searle (1975) basically takes the same line. Currie (2014) has further articulated his idea, by saying that the fictionality of works comes in degrees and that the degree of fictionality of a work as whole supervenes on its intentional profile.

21 Cf. Stock (2011), Friend (2008, 2011). Yet Friend appeals to a reason that does not seem to me very cogent: for her, it seems that only things partially made by a natural kind may be patchworked items, thus a patchwork partially made by fiction, which definitely is no natural kind, would not be such. Cf. (2008:163-4), (2011:166).

22 Stock (2011) does not allow for this concession as well. For in her mind, although it may be the case that a content featuring a fictional work is both imagined and believed, in order for the work that includes that content to be fictional, it must contain some other content connected to the previous one that is just imagined and not believed. According to Friend (2008:160-1), (2011:171-3), however, this idea does not provide sufficient conditions in order for something to be fictional: even nonfictional works may well induce one not to believe their whole content but just to imagine it. I also doubt that this is a 
First of all, as I just said, it may well be the case that one and the same text as a whole is uttered both fictionally and nonfictionally. When this is the case, two works stem out of the same text. In this respect, Walton's claim (1990:87-90) that something originally designed to be a work of one kind may also turn out to be a work of the other kind appears to be justified. ${ }^{23}$

Besides, when a text as a whole is not surrounded by a double perspective, a fictional and a nonfictional one, it may still be the case that such a text amounts as a whole to a work of just one kind and yet some of its sentences are uttered not only in the way enabling it to be a work of that kind, but also in the other way. Since just a part of those sentences are uttered in this second way while those sentences as a whole are uttered in the first way, it is normally taken for granted that just one work stems out of such sentences. ${ }^{24}$ Or at least, this is the way we take how things stand in a lot of cases. On the one hand, this is the case of historical novels. The text constituting one such novel contains some sentences that are nonfictionally uttered. Yet those very sentences are also taken together with the other sentences of the text, which are uttered merely fictionally, in order for a fictional story to be told. As a result, the text is fictionally uttered as a whole, thereby amounting just to a fictional work; the fact that just some bits of that text are also uttered nonfictionally does not normally prompt also a nonfictional work to arise out of it. But on the other hand, it is also the case of literary history, new journalism, and even scientific treatises. The text constituting any such item contains some

necessary requirement for a work to be fictional. A way to justify this doubt is to appeal to context shifts that may make one and the same amount of content be both actually believed qua featuring a nonfictional work and made believe, i.e., believed in a fictional context, qua featuring a fictional work. See the next Section.

23 One may object that this way of putting things obliterates the distinction between what is a fictional work and what is treated as such (cf. e.g. Currie 1990:36, Lamarque \& Olsen 1994:48). Yet since this way is neutral between the speechact-theoretical and the pretense-theoretical approach and the objection only concerns the latter approach, such an objection does not arise here. As how to deal with that objection in the minimally contextualist approach that resumes the pretense-theoretical approach, see the next Section.

24 I say normally, for one can figure out cases in which even though, unlike utterance of the one kind, utterances of the other kind cover the whole text, not only the latter utterances determine a work of a certain kind, but also the former utterances are taken to determine a (mini) work of the other kind. See the next Section. 
sentences that are fictionally uttered, yet those very sentences are also taken together with the other sentences of the text, which are uttered merely nonfictionally, in order for a nonfictional story to be told. As a result, the text is nonfictionally uttered as a whole, thereby amounting just to a nonfictional work; the fact that just some bits of that text are also uttered fictionally does not normally prompt also a fictional work to arise out of it.

Finally, it may be the case that the same collection of sentences constituting a text is partially uttered fictionally and partially uttered non-fictionally. Since no way of uttering such sentences prevails, then one and the same text prompts again different works, a fictional and a nonfictional one, just as in the first case above. Yet this time the two works stem out not of that text as a whole, but of its respective parts.

All in all, therefore, there is no patchworked work arising out of one and the same text.

Needless to say, an opponent of the utterance approach will be dissatisfied with this way of dealing with the 'patchwork' problem. What makes it the case, she may wonder, that a whole text, not just some of its utterances, is uttered in a way - fictional, nonfictional - that makes it amount to (at least) a work of the same kind - fictional, nonfictional? Coming back to (1), is this not a mere geographical description of a particular area of Lombardy, so that nothing fictional arises out of it? Conversely, is not (2) just a bit of fictional invention that is not uttered in a nonfictional way? Thus, if the work is of a certain kind - fictional, nonfictional - this does not depend on the fact that all its sentences are uttered in the same way - fictional, nonfictional - for there is no such fact. If this is the case, moreover, why when a text is uttered partially in one way partially in another, we have to speak of two works stemming out of it rather than of a single patch worked work? As Friend nicely sums up the problem, "an approach that sheds no real light on how we move from the parts to the whole is inadequate" (2012:186).

In order for a defender of the utterance approach to deal with this problem, I have in the next Section to specify better the mechanism that makes utterances fictional vs. nonfictional. 


\section{The Nature of Fiction}

In this Section, first, I want to argue that a minimally contextualist account is the best way to develop this utterance approach. Second, I want to show how this account may turn out to be helpful in order to understand the nature of fiction.

As I said before, the utterance approach may be developed in two ways: either by appealing to speech acts or by appealing to context shifts. The first way is definitely pragmatic: as most people say, speech acts capture a level of significance for sentential utterances that goes beyond the semantic level they involve, which is paradigmatically given in truth-conditional terms. The second way is basically semantic. Granted, it appeals to contexts, from it draws a distinction between fictional and nonfictional contexts. Yet such an appeal is minimal, for any such context is just a narrow contexts of interpretation, i.e., a set of a definite number of parameters that, given the linguistic meaning of a sentence, automatically yield the truth-conditions such a sentence possesses in that context. In this respect, a sentence - narrow context pair is just a theoretical representation of an utterance. ${ }^{25}$

Thus, according to the first way, the difference between a fictional and a nonfictional utterance, hence between a fictional and a nonfictional work, is pragmatic as well. A sentence that has certain truth-conditions may be uttered either in a fictional way so as to perform a certain sui generis speech act or in a nonfictional way so as to perform another speech act (typically, an assertion).

Yet according to the second way, the difference between a fictional and a nonfictional utterance, hence between a fictional and a nonfictional work, is semantic as well. On the one hand, a fictional utterance is an utterance of a certain sentence in a certain fictional narrow context that contextually yields that sentence certain fictional truth-conditions - the sentence is true in a certain fictional world, the world that saturates the corresponding parameter of that fictional context, iff things unfold in a certain way in that world, the way it says. On the other hand, a nonfictional utterance is an utterance of a certain sentence in a certain nonfic-

25 On this, cf. Predelli (2005). 
tional narrow context that contextually yields that sentence certain real truth-conditions - the sentence is true in the actual world, the world that saturates the corresponding parameter of that nonfictional context, iff things unfold in that world as it says. ${ }^{26}$

Take e.g. (1). Uttered in the fictional context of Manzoni's tale, the sentence is true in the world of that tale iff the relevant branch of a certain lake, the Lake of Como, has a certain configuration there. Yet uttered in a nonfictional context, (1) is actually true iff the Lake of Como has a certain configuration in the actual world. Since things so unfold both in the world of Manzoni's tale and in the actual world, (1) is (in its respective context) fictionally and actually true respectively. Now take (2). Uttered in a nonfictional context, the sentence is actually true iff a certain individual named "Arthur" both succeeded another individual named "Uther" and besieged a third individual named "Colgrin" in the actual world. As there actually is no such individual, the sentence in such a context is false or truth-valueless (depending on your favourite semantics of proper names). Yet when uttered in a fictional context, the context of Geoffrey's tale, the sentence is fictionally true iff Arthur succeeded Uther and besieged Colgrin in the world of that tale. As in the world of that tale there are all such unactual individuals, the sentence (in that context) is fictionally true.

I claim that the second way, the minimally contextual one, is better than the first one. There are at least three reasons for me to make such a claim. First of all, the notion of a work is basically semantic. The nicest theoretical representation of a work indeed consists in taking it as a set of hybrid entities, notably entities-cum-meaning, i.e., linguistic structures plus their semantic interpretation. This conforms to the second way: for

26 True enough, one might rather appeal to wide contexts, i.e., the concrete situations of discourse, and claim in a maximally contextualist vein that different wide contexts provide different truth-conditions - fictional, real - for the sentences involved. Yet an economy motto suggests itself that says, don't appeal to wide contexts if you can appeal to narrow contexts. There must be a reason as to why one has to prefer wide to narrow context. One such reason might be that ontologically speaking appealing to fictional worlds as parameters of narrow contexts is a bad move, since fictional worlds may even be impossible ones (I owe this suggestion to Fred Kroon.) Yet if one endorses an Ersatzist metaphysics of fictional worlds, the ontological cost of appealing to such worlds may be a price worth paying. 
it, a work is set of entities made of utterances (sentences in narrow context) plus their truth-conditional interpretation. ${ }^{27}$

Moreover, the separation between nonfictional contexts and fictional contexts may well explain why one may entertain both a belief and a make-belief attitude with respect to the same text. One believes the nonfictional content that text expresses in a real context - i.e., the real truth-conditions of its sentences in that context - while making believe the fictional content that text expresses in the fictional context - i.e., the fictional truth-conditions of its sentences in that context -, or, which is the same, believing in this context this very content. Now, nothing prevents the nonfictional content and the fictional content expressed by a text in their respective contexts from being identical, as is the case with the above (1). Pace Gibson (2007:166), there is in general no problem in believing and making believe one and the same content. ${ }^{28}$ Yet this compatibility is even more warranted, I hasten to add, if such attitudes are related to different contexts, a nonfictional and a fictional one. I may well both actually believe and supposedly believe that Hitler is born, if this means that in an actual situation I believe what I also believe in a possible situation. The same may well happen also when the situations in question are an actual and a fictional one.

27 I slightly modify the account I provided in Voltolini (2006b), where I took what I there called fictional works as sets of hybrid entities that result out of the combination of sentences plus their truthconditional meaning. To be sure, what I there meant by fictional works is different from what I here call fictional works, because the former are constituted by fictional entities, abstract entities that figure in the overall domain of what there is, while the latter are characteristically constituted by unactual entities, concrete entities that do not figure in the overall domain of what there is. To be faithful to this distinction, I should label those fictional works as fictional stories and these fictional works as fictional tales. Yet for the purposes of this paper let me leave this complication aside.

28 Cf. also Davies (2012:72-3), (2015:41), Friend (2008:156), Stock (2011:149-50). To be sure, Gibson specifies that the problem concerns just one and the same appreciative state, as he labels it: in that very state one cannot both believe and make-believe the same thing (2007:168). If this specification is taken to imply that one can both believe and imaginarily believe the same thing yet in different (narrow) contexts, I am fine with it. Yet if it is taken to imply that one cannot both believe and imaginarily believe the same thing within one and the same mental state, I still disagree with Gibson. For, as we will see later, within one and the same metarepresentational state of make-believe one can entertain one and the same doxastic representation both as to the actual world and as to an unactual, imaginary, world. 
To this way of putting things, an opponent to the utterance approach may still reply that, when a fictional work that is definitely recognized as such is at stake, it may be the case that a make-believe attitude just surrounds some of parts of it, yet not the work as a whole. Let's go back to Manzoni's The Betrothed. Even if it is a fictional work recognized as such, it may well be described as being such that some of its parts are just believed, not made believe. This is for instance the case with its already recalled (1), which is just a true description of some bits of Lombardy. In reading (1), people just believe that the Lake of Como has such a configuration, yet they do not also make believe that it has that configuration. ${ }^{29}$

With respect to this problem, some defenders of the utterance approach, notably David Davies $(2012,2015)$, have bitten the bullet and claimed that what holds for fictional narrations does not have to hold for fictional works. A fictional narration is that part of a fictional work that mobilizes a fictive content, a content that depends on one's making believe that things unfold in a certain way: a de dicto form of make-believe. Yet a fictional work may also be made of parts that involve a real setting. As to such parts, of such a setting, one still makes believe that it is in a certain way, a de re form of make-believe. Yet there is no corresponding de dicto make-belief that something is in a certain way. Thus, although one may still say that, in a broad sense, the relevant sentences of the work concerning such a setting are fictionally true, such sentences have no fictive content arising out of a de dicto form of make-believe, so that they are not fictionally true in a narrow sense. This is precisely the case e.g. with (1): since it concerns the real setting of The Betrothed, it is fictionally true just in a broad sense. ${ }^{30}$

The distinction between those two forms of make-believe is not new. It traces back to Evans' (1982) original idea that there are two kinds of make-believe game, creative make believe games in which one makes believe that a certain unactual something is so and so and conservative

29 Cf. Gibson (2007:165-6), Friend (2008:158-61). Mutatis mutandis, says Friend, historical works that are recognized as such may contain parts that are merely made believe, not believed.

30 Cf. Davies (2012:78-83), (2015:45-7). Davies labels the theory stemming out of this distinction between fictional narrations and fictional works "the refined fictive utterance view". Cf. (2012:80), (2015:45-7). 
make believe games in which of a certain actual something, one makes believe that is so and so. This distinction is reprised by Walton (1993) when he says that, over and above games of make-believe in which props only support a certain make-believe activity, there also are prop-oriented games of make-believe that concerns those very props.

Yet once a defender of the utterance approach appeals to context shifts, she may well say that such a distinction does not justify a distinction between fictional narrations and fictional works. First of all, in the parts of a work that trace back to sentences that are affected by a creative make-believe game, it happens that the fictional truth-conditions those sentences have when paired with a fictional context differ from the real truth-conditions those sentences have when paired with a nonfictional context. In Davies' terms, therefore, that make-believe game mobilizes for those sentences a fictive content, i.e., certain fictional truth-conditions, different from the real content that is mobilized for those sentences out of that game, i.e., certain real truth-conditions. For the first truth-conditions involve unactual individuals, while the second truth-conditions involve no individual at all. Yet moreover, in the parts of a work that trace back to sentences that are affected by a conservative make-believe game, there still is a fictional context in which those sentences possess fictional truth-conditions. This is the very same fictional context as the one the previous sentences, those affected by a creative make-believe game, were paired with, for the 'world' parameter is still saturated by the same fictional world. ${ }^{31}$ Yet these fictional truth-conditions are the same as the real truth-conditions such sentences possess in a nonfictional context. Hence, that make-believe game still mobilizes a fictive content for those sentences, yet that content is the same as the real content that is mobilized for them out of that game; indeed, such truth-conditions involve the same actual individuals, the individuals of what Davies calls a real setting. So, this fictive content just extends

31 One may object that in order for a narrow content to be the same, it is not enough that its world is the same one, for the values of the other parameters of such a context agent, space, time - may change. Yet if the agent of a fictional context is not the real, but an ideal narrator as Currie (1990) suggests, then all the other values of the parameters of a fictional context may remain the same across the sentences that it affects; not only the agent, but also the place and the time from which she supposedly utters those sentences may remain the same. 
the fictive content the previous creative make-believe game mobilizes. Finally, that conservative make-believe game affects such sentences not only when they are fictionally true in that fictional context and actually false in a nonfictional context, as Davies maintains, for in that game, one makes believe of such actual individuals that they are as they are not in the actual world. Rather, it also affects such sentences when they are both fictionally true in that very same fictional context and actually true in a nonfictional context. Pace Davies, actual truths about a real setting are imported as fictional truths, for one makes believe of the actual individuals of such a setting that they are as they indeed are in the actual world. As a consequence, there is no need to draw a distinction between a fictional narrative and a fictional work. For the fictional work results out of the whole fictional truth-conditions that all the sentences it is based on respectively have when paired with a certain fictional context.

Let us go back to The Betrothed once again and consider the sentence that introduces one of its main protagonists, Don Abbondio, the fearful curate:

(3) Towards evening [...], Don Abbondio was returning slowly towards his home.

Clearly enough, a creative make-believe game affects (3): one makes believe that a certain individual named "Don Abbondio" slowly returns home towards evening. Thus, (3) has fictional truth-conditions, once it is interpreted in a fictional context whose 'world' parameter is saturated by the world of Manzoni's tale. These truth-conditions depend on the reference the name "Don Abbondio" has within such a context, i.e., a certain unactual individual. As in the world of that tale this individual slowly returns home towards evening, that sentence so interpreted is fictionally true. Such truth-conditions clearly differ from those (3) has once it is interpreted in a nonfictional context whose 'world' parameter is saturated by the actual world, where "Don Abbondio" refers to nothing at all. Depending on the semantics you appeal to, such a sentence in that context turns out to be actually false or truth-valueless. Now consider:

(4) From village to village, from the heights down to the margin of the lake, there are innumerable roads and paths 
[...] One of these pathways [is such that it] branche[s] like the letter $Y$ into two narrow paths [...] At the confluence [...] of the two narrow lanes, there were two men.

This time, a conservative make-believe game affects (4): of a certain actual pathway along the Lake of Como, one makes believe that at a branch of its in two narrow paths, two men were placed, what the tale will later reveal to be two dangerous bravoes. Thus, (4) has fictional truth-conditions once it is interpreted in a fictional context. Actually, this is the same fictional context as the one (3) is paired with, for it is again the context whose world is the world of Manzoni's tale. Yet such truth-conditions are the same as the real truth-conditions (4) once it is interpreted in a nonfictional context whose world is the actual world. Simply, (4) when paired with that fictional context is fictionally true, for in the world of Manzoni's tale that pathway has a branch where two bravoes are placed, yet when paired with that nonfictional context it is actually false, for in the actual world that pathway has no bravoes at such a branch. Finally, let us go back to (1). Pace Davies, (1) may well be interpreted in a fictional context, actually the same fictional context as the one (3) and (4) are paired with, so that it has fictional truth-conditions as well: it is fictionally true iff the Lake of Como has such a configuration in the world of Manzoni's tale. For the previous conservative make-believe game affecting (3) also affects (4). Yet not only those truth-conditions are the same as the real truth-conditions (1) has when interpreted in a nonfictional context - it is true in the actual world iff the lake of Como actually has such a configuration - but also (1) is both fictionally and actually true: both in the world of Manzoni's tale and in the actual world, the lake has such a configuration. As a result, it is not the case that there is a fictive content that just determines a fictional narration, notably a part of Manzoni's The Betrothed, as Davies holds; namely, the fictive content stemming out of sentences like (3). Rather, not only sentences like (3), but also sentences like (4) and (1) are paired with a fictional context, actually the very same context, so that they all constitute the fictive content determining the overall fictional work of The Betrothed.

Furthermore, on the basis of the above reflections, a minimally contextualist defender of the utterance approach may address the problems 
with which I ended the previous Section. Once one performs a semantically relevant context shift, one mobilizes a semantic fictive content for all the sentences that are affected by this shift that is at most coincidentally identical with the semantic real content that is mobilized by possibly the very same sentences when uttered in a nonfictional context. Thus, such a fictive content may well determine a work of its own both when the shift concerns a sentential text as a whole and when it concerns just parts of it. Indeed, one may legitimately speak of different works, a fictional and a nonfictional one, both in the first and in the third case envisaged in the previous Section; namely, both when the context shift concerns the text as a whole, thereby making two works out of the whole text - the relevant make-believe game, whether creative or conservative, affects that text as a whole - and when it concerns just a part of it, thereby making two works out of different parts of the same text - the relevant make-believe game affects just some parts of that text. Moreover, in the second of the three cases envisaged in the previous Section, namely when a certain context of interpretation affects a certain text as a whole and another such context affects it only partially (the case of historical novels on the one hand and new journalism on the other), it may well suit our ordinary practices to speak of (fictional, nonfictional) narrations, in Davies' sense, for the collections of (fictional, nonfictional) utterances that cover just a part of a text when the opposite kind of utterances covers that text as a whole thereby generating just a (fictional, nonfictional) work. Recall, however, that our speaking in such a case just of one work, the work stemming out of the context of interpretation that affects a text as whole, plus one narration stemming out of the different context of interpretation that affects that text merely partially, is a basically pragmatic matter. For such a way of speaking depends on the fact that as to meaning generation, one context numerically prevails on the other, for it is paired with the whole text insofar as, as we have just seen, the whole text is taken as telling a certain story (fictional, nonfictional). Yet if we wanted, nothing theoretically prevents us from speaking also in such a case not just of one work and one narration, but of two works, notably a longer and a shorter one. Sometimes, this precisely happens. Consider e.g. Robert Musil's The Man without Qualities, which amounts both to a fictional 
work - one of the masterpieces of 20th century Western literature (concerning all its sentences qua fictionally uttered) and to a nonfictional work, notably a philosophical treatise (concerning just those sentences of its text qua nonfictionally uttered). A docufiction can be the opposite example (a nonfictional work as a whole, a fictional work just as to the parts of its text that also elicit a fictional interpretation).

At this point, however, someone - possibly, a defender of the pragmatic way of defending the utterance approach - may raise the following objection. Appealing to a speech act, even a sui generis one, gives a substantive characterization of what a fictional utterance is, no matter whether this speech act is cashed out in intentionalist or in normative terms. For the fact that an utterance is fictional is explained in terms of its being an utterance that performs such an act. Yet qualifying an utterance as fictional in terms of its being interpreted in a fictional context, while such a context is further qualified in terms of its having its 'world' parameter saturated by a fictional world, seems to give no substantive information as to what a fictional utterance is, but it simply pushes the problem one step back. What is for a world to be fictional?

This objection is well grounded. Speaking of a context shift and appealing to a fictional context definitely gives a necessary condition in order for an utterance to be fictional, but not a sufficient one. Sentences may be also uttered e.g. in oneiric contexts, where an oneiric context is a context whose 'world' parameter is saturated by an oneiric world, the world in which that sentence in that context is true (or false). Yet their similarity notwithstanding, ${ }^{32}$ a dream and a fiction are not the same thing. So, what makes it the case that when a fictional utterance is at stake, the context shift in question is the relevant context shift, the shift that makes that utterance fictional (rather than oneiric, etc.)?

Borrowing a suggestion that is actually proposed by sustainers of the pragmatic way of defending the utterance approach, one might say that the context shift is fictional for it is based on a fictive stance, which differs from the nonfictive stance that surrounds a nonfictional context. ${ }^{33}$

32 For an analogous comparison between dreams and fictions cf. Walton (1990:43-50).

33 This idea originally comes from Lamarque \& Olsen (1994), who hold that such a stance applies to texts in general, even if they agree with Currie (1990) that fictionality 
Moreover, these different stances may be basically qualified in terms of the attitudes one takes with respect to a text. If a text is evaluated as to its faithfulness to real facts, that stance is the nonfictive one. Yet if it is not so evaluated, that opposite stance is the fictive one. ${ }^{34}$

Truly enough, whenever there is a semantically relevant context shift, there is a further contextual yet pre-semantic reason in order for a sentence to be so shifted. ${ }^{35}$ Yet when meant in the above terms, a stance switch is not sufficient for a shift to be fictional. Like any dream, a daydreaming involves a context shift that may well depend on endorsing a stance in which no representation in the daydream is evaluated in terms of its being faithful to real facts. Yet as we have just seen, a dream, even a daydream, is no fiction at all.

In the case of a shift to a fictional context, therefore, we have to look for another pre-semantic reason to ground such a shift. Up to now, I have implicitly agreed with Walton in holding that such a reason consists in the fact that people play a certain make-believe game involving the text that is affected by the shift. Yet to my mind, it would be better to say that such a reason consists in the fact that the relevant utterer engages herself in an act of make-believe concerning the relevant sentences. Indeed for me, the best way of conceiving that act is taking it not as a normative practice $a$ la Walton (1990), i.e., a practice in which one is prescribed to imagine something, but as a mental state à la Currie (1990), provided that it is conceived as a mental state of a particular kind: a metarepresentation. Whenever one engages in an act of make-believe, one activates i) a (series of) simple representation(s) of the actual world, ii) another (series of) simple representation(s) yet of an unactual world - this/these is/are the representation(s) whose linguistic expression involves a context shift - and iii) a metarepresentation that the first representation(s) and the second representation(s) concern different worlds. When this representational triad involves two series of simple representations, as to the utterances that express the second series, the series that represents

lies in the fictive intent with which sentence are uttered.

34 Davies (2007) qualifies those attitudes in terms of the fidelity vs. the nonfidelity constraint.

35 For the idea of a pre-semantic role of context see Perry (1997). 
an unactual world, we are legitimated to speak of a fictional narration or of a fictional work.

For instance, in the classical example originally provided by Leslie (1987), if one makes believe that a certain banana is a telephone, she activates a certain simple representation concerning the actual world (the representation linguistically expressed by an utterance of the sentence "this is a banana"), another simple representation concerning an unactual world (the representation linguistically expressed by a contextually shifted utterance of the sentence "this is a telephone"), plus a metarepresentation to the effect that the first representation and the second representation concern different worlds. This example corresponds to a case of a creative make-believe game, in which a representation of an unactual reality involving an unactual telephone is activated on the basis of a different representation of the actual world involving an actual banana, which according to Walton (1990) simply plays the role of a prop in that game. Truly enough, in the case of a conservative make-believe game, we have just one simple representation, for instance in the case of (1) we only mobilize a representation involving the actual lake of Como, which is not only a prop in the game but also what that game concerns. Yet also in such case, that representation is addressed both to an unactual world (thereby involving a context shift for its linguistic expression) and to the actual world respectively. In that sense, unlike the previous case, one and the same representation is both actually believed and imaginarily believed. Yet moreover, what makes it a genuine case of make-believe is again the fact that over and above such a representation, one also entertains a metarepresentation that in its distinct activations, that very representation respectively concerns different worlds. These examples provide cases where just a fictional utterance is concerned. To pass from fictional utterances to fictional narrations or even to fictional works, one merely has to consider cases where the metarepresentational act of make-believe is extended so as to cover both a series of simple representations of the actual world and a series of simple representations of an unactual world - possibly, as we have just seen, the very same representations those whose linguistic expressions are contextually shifted.

Certainly enough, no such metarepresentational machinery is involved in, say, dreaming. In that case, one only activates a representation of an 
unactual world; not even a representation of the actual world is in force in virtue of her dreaming, one is representationally disconnected from the actual world. For instance, if one dreams of a telephone in front of her, only the representation of an unactual world, a telephoneful world, of the kind expressed by (a shifted utterance of) "This is a telephone" is active; no representation of the actual world arises. This is why dreaming is not the same as making believe.

Yet such a metarepresentational machinery is precisely required in order for make-believe to arise. For merely activating two simple representations, one for the actual world and another one for the unactual world, is not enough in order for one to entertain an act of make-believe. Consider a dissociated subject, namely someone who has some positive understanding of the actual world along with some mental aberrations. This subject typically entertains representations of the actual world along with representations of an unactual world. For instance, someone who is affected by the Capgras syndrome both entertains a representation like "This is a relative of mine" of the actual world addressed to some actual individual along with a representation like "This is an impostor that has replaced my relative" of an unactual world yet addressed to the very same individual. Clearly enough, such a subject is not make-believing. For she fails to entertain a third representation, i.e., a metarepresentation that the two simple representations above concern different worlds. It is precisely because she lacks this metarepresentation that she performs a confused form of behavior on the basis of the above contrasting simple representations, rather than performing a coherent form of behavior that inhibits the causal import of the second representation, as any proper make-believer does. For instance, one does not panically get out of a cinema while attending a scary movie on a green slime, but she rather goes on chewing popcorns, for she knows that, unlike the representation "This is a cinema screen", the representation "This is a green slime" 36 is addressed to an unactual individual. ${ }^{37}$

36 The example of the green slime notoriously comes from Walton (1978).

37 Thus, so-called' multiple model' theories of make-believe, which claim that make-believe consists in merely activating different representational models, one addressed to the 
As this example shows, this kind of metarepresentation is not merely necessary, but also sufficient, for an utterance of a sentence, hence a text, to be fictional. Consider the ordinary case in which a subject undergoes the illusion, recognized as such, that the stick immersed in the glass of water she faces is bent. Clearly enough, uttering "this is bent" while recognizing the falsity of what she utters activates in her a metarepresentation that however amounts to no form of make-believe. Simply, by means of the above utterance the subject entertains a false representation of the actual world, which she moreover correctly represents as false. Yet when the subject firstly utters "this is not bent" as addressed to the actual world, secondly utters "this is bent" as addressed to a nonactual world, and finally recognizes that those two representations address different worlds, she entertains a metarepresentation that amounts to a form of make-believe of the same kind as the one mobilized in the 'green slime' case. Only then, uttering "this is bent" on that subject's part counts as fictional.

This way of putting things has some advantages. First, running metarepresentationally may tell make-believe from other forms of imaginings. Friend has repeatedly criticized Walton for his appealing, in his conception of make-believe, to a notion of imagination that is definitely broader than the kind of imagination fiction involves: walt-fiction, as she (2008:152) nicely labels it. Not any form of imagination, says Friend, determine fiction. "Vividly told nonfiction narratives invite us to imagine what it was like for people to live in different times and places, to undergo wonderful or horrible experiences, and so on." (Friend 2012:183). ${ }^{38}$ One may well agree with Friend if one accounts for the narrower kind of imagination that fiction involves in terms of the present metarepresentational account of make-believe. Mere imagining, however vividly, a certain scenario is not enough for fiction. In order to make that imagination a fic-

actual world and another addressed to an imaginary world (Perner 1991, Nichols \& Stich 2003), are unable to account for make-believe. As Friend (2008:156) brilliantly intuited. The metarepresentational approach to make-believe has been originally defended by Leslie (1987). See also Lillard (2002:104): "a pretender must be aware of the actual situation and the nonactual, represented one, or else (s)he is mistaken, not pretending". For details on this, along with my preferred version of metarepresentationalism, cf. Meini-Voltolini (2010).

38 See also Friend (2008:153-4), (2011:164). 
tional kind of imagination, one must not only imagine that scenario, but also represent a real scenario and metarepresent that the two representations concern different scenarios.

Second, running metarepresentationally may successfully deal with myths recognized as such in terms of fictional works as any other. Pace Currie (1990) and Lamarque \& Olsen (1994), this assimilation of myths with standard fictional works does not lead to a problematic collapse of being a fictional work onto being treated as such. Rather, focusing on myths recognized as such paradigmatically shows what is the source for a fictional work in general. In myths, one starts from uttering nonfictionally certain sentences, thereby entertaining representations addressed at the actual world, e.g. the one expressed by the following utterance of:

(5) Zeus lives on top of Mt. Olympus.

This utterance of (5) is presumably actually false or truthvalueless, for in the actual world there is no one named "Zeus" living on top of Mt.Olympus. Yet in order for a myth to be recognized as such, one must first of all flank the above utterance with another utterance of that very sentence, say another utterance of (5) one produces while entertaining again that very representation yet addressed to an unactual world. This utterance of (5) involves a context shift and is true in the unactual world of the relevant context, for in that world there exists a certain individual named "Zeus" that lives on the top of Mt.Olympus: the unactual father of all gods. Besides, in order for that myth recognition to take place, something more must occur, i.e., what makes that utterance of (5) fictional. This is to say, one must entertain another representation, i.e., the metarepresentation that the simple representation above concerns the actual world at one time and an actual world at another time. An analogous make-believe operation will be performed with the other utterances that constitute the myth. Thus in the end, myths are just texts that, normally at least, are uttered fictionally not when they are written, but afterwards, namely, once they are surrounded by the proper metarepresentational state of make-believe.

Let me take stock. By ultimately accounting for the fictionality of an utterance, hence of a work, in terms of the utterer's entertaining a 
metarepresentational act of make-believe, I end up holding that the issue of the nature of fiction, or in other terms, the issue of what constitutes the fiction/nonfiction divide, cannot be clarified in terms of the fictional/ nonfictional works distinction, hence in terms of the distinction between fictional and nonfictional utterances. For things rather go the other way around. Granted, what grounds the fictional/nonfictional works distinction is the distinction between fictional and nonfictional utterances. Yet what makes an utterance fictional is what explains the fiction/nonfiction divide, namely the fact that its utterer entertains a metarepresentational act of make-believe in which not only she represents both the actual world and a fictional world, but also she metarepresents that the second representation is a representation of a world different from the world the first representation represents. Consider this metarepresentational awareness as the little voice whispering to you: "it's only make-believe", as the famous song says. ${ }^{39}$

\section{References}

Currie, G., 1990, The Nature of Fiction. Cambridge, Cambridge University Press.

-- 2014, "Standing in the Last Ditch: On the Communicative Intentions of Fiction Makers". Journal of Aesthetics and Art Criticism, 72, 351-63.

Davies, D., 2007, Aesthetics and Literature. London, Continuum.

--- 2012, "Fictionality, Fictive Utterance, and the Assertive Author". In G. Currie, P. Kotá'tko \& M. Pokorný (eds.), Mimesis: Metaphysics, Cognition, Pragmatics. London, College Publications, 61-85.

--- 2015, "Fictive Utterance and the Fictionality of Narratives and Works". British Journal of Aesthetics, 55, 39-55.

39 This paper has been presented at the Conferences XLIV Congresso AISS, September 30 - October 2, 2016, Università eCampus, Novedrate (Como), and Philosophy of Language (I): Semantics of Fictional Discourse, Institute of Philosophy, Slovak Academy of Sciences, October 20-21, 2016, Bratislava. I thank the participants for their useful questions. I also thank Fred Kroon for some important comments to a previous version of this paper. I am finally grateful to Carola Barbero, John Gibson, Stacie Friend, Wolfgang Huemer for the insigthful discussions had with them on such a pleasant topic. 
Deutsch, H., 2000, "Making Up Stories" In T. Hofweber \& A. Everett (eds.), Empty Names, Fiction, and the Puzzles of Non-Existence. Stanford, CA, CSLI Publications, 17-36.

--- 2013, "Friend on Making Up Stories". Proceedings of the Aristotelian Society, 113, 365-70.

Evans, G., 1982, The Varieties of Reference. Oxford, Clarendon Press.

Friend, S., 2008, "Imagining Fact and Fiction". In K. Stock \& K. Thomson-Jones (eds.), New Waves in Aesthetics. New York, Palgrave Macmillan, 150-69.

--- 2011 , "Fictive Utterance and Imagining". Proceedings of the Aristotelian Society Supplementary Volume, 85, 163-80.

--- 2012, "Fiction as a Genre". Proceedings of the Aristotelian Society, $112,179-209$.

Garcia-Carpintero, M., 2013, "Norms of Fiction-Making". British Journal of Aesthetics, 53, 339-57.

Geertz, C., 1988, Works and Lives: The Anthropologist as Author. Stanford, CA, Stanford University Press.

Gibson, J., 2007, Fiction and the Weave of Life. Oxford, Oxford University Press.

Kroon, F. \& Voltolini, A., 2016, "Fiction". In E.N. Zalta (ed.), The Stanford Encyclopedia of Philosophy, URL = http://plato.stanford.edu/archives/ fall2011/entries/fiction/

Lamarque, P. \& Olsen, S.H., 1994, Truth, Fiction and Literature. Oxford, Clarendon Press.

Leslie, A. M., 1987, "Pretense and Representation: The Origins of 'Theory of Mind'”. Psychological Review, 94. 412-26.

Lillard, A., 2002, “Just through the Looking Glass: Children's Understanding of Pretence". In: R.W. Mitchell (ed.), Pretending and Imagination in Animals and Children. Cambridge, Cambridge University Press, 102-14.

Meini, C. \& Voltolini, A., 2010, "How Pretence Can Really Be Metarepresentational". Mind and Society, 9, 31-58. 
Nichols S. \& Stich S., 2003, Mindreading. Oxford, Oxford University Press

Perner, J., 1991, Understanding the Representational Mind. Cambridge MA, The MIT Press.

Perry, J., 1997, "Indexicals and Demonstratives." In R. Hale \& C. Wright (eds.), Companion to the Philosophy of Language. Oxford, Blackwel, 586612.

Predelli, S., 2005, Contexts. Oxford, Oxford University Press.

Recanati, F., 2000, Oratio Obliqua, Oratio Recta. Cambridge MA, The MIT Press.

Reed, A.W., 2006, Reed Book of Maori Exploration. Auckland, Reed Books.

Sainsbury, R.M., 2009, Fiction and Fictionalism. London, Routledge.

Searle, J., 1975, "The Logical Status of Fictional Discourse". New Literary History. 6, 319-32.

Stock, K., 2011 , "Fictive Utterance and Imagining". Proceedings of the Aristotelian Society Supplementary Volume, 85, 145-61.

Voltolini, A., 2006a, "Fiction as a Base of Interpretation Contexts". Synthese, 153, 23-47.

--- 2006b, How Ficta Follow Fiction. A Syncretistic Account of Fictional Entities. Dordrecht, Springer.

Walton, K.L., 1970, “Categories of Art". Philosophical Review, 79, 334-67.

--- 1978, "Fearing Fictions". The Journal of Philosophy, 75, 5-25.

--- 1990, Mimesis as Make-Believe: On the Foundations of the Representational Arts. Cambridge, MA, Harvard University Press.

--- 1993, "Metaphor and Prop Oriented Make Believe". The European Journal of Philosophy, 1, 39-57. 